Çanakkale Onsekiz Mart Üniversitesi Fen Bilimleri Enstitüsü Dergisi, 2016:2, 2, 01-19

Çanakkale Onsekiz Mart University, Journal of Graduate School of Natural and Applied Sciences, 2016:2, 2, 01-19

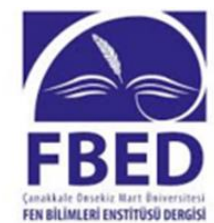

\title{
Kalp Hastaları İçin Bulut Bilişim Temelli Erken Uyarı Sistemi
}

\author{
Ömer Ery1lmaz*, İsmail Kahraman, Mustafa Şahin \\ Çanakkale Onsekiz Mart Üniversitesi, Mühendislik Fakültesi, \\ Bilgisayar Mühendisliği ABD, Çanakkale
}

\section{Özet}

Dünyada ve ülkemizde ölümle sonuçlanan vakaların başında kardiyak aciller yer almaktadır. Kardiyak acillerde zamanında ve etkin acil bakım uygulayabilmek çok önemlidir. Kalp hastalıkları en kısa sürede tanımlanabilmeli, tedaviye yönelik çalışmalar başlatılmalı ve en yakın sağlık merkezi ile koordinasyon sağlanıp sevkiyatı yapılmalıdır. Bu çalışmada kalp rahatsızlığı olan kişilerin uzaktan takibi için hasta, doktor ve sağlık merkezini kapsayan akıllı bir bilgi sistemi oluşturulmuş ve oluşabilecek herhangi bir anomali durumunda hasta, yakınları, doktor ve ilgili sağlık merkezlerinin erken uyarı amaçlı bilgilendirilmesi sağlanmıştır. $\mathrm{Bu}$ kapsamda kalp hastalıklarının tanımlanması sürecinde yoğun kullanılan parametrelerin ölçümü için donanımsal bileşenler EKG cihazı, nabız ölçer ve tansiyon ölçer gibi cihazlardır. Bu bağlamda mevcut çalışmada nabız ölçer cihazı donanımsal ve yazılımsal olarak gerçekleştirilmiştir. Hasta kayıtları için esneklik, ölçeklenebilirlik, performans/fiyat avantajları yanında mobil ve web ortamını tek merkezden kullanmak ve yönetmek için avantajlar sağlayan merkezi bulut sistemi kullanılmıştır. Hastadan elde edilen nabız verileri bulut sistemine hastanın geçmiş kayıtları olarak kayıt edilmiş ve analiz edilmiştir. Bu analizler sonucunda acil

*Sorumlu Yazar (Corresponding Author): Ömer Eryılmaz (e-posta:omer-eryilmaz@hotmail.com) 
durumların otomatik olarak sistem tarafindan tespiti ve ilgili yerlere bildirimi gerçekleştirilmiştir.

Anahtar Sözcükler: kalp hastalıkları, bulut bilişim, mobil uygulama, nabız takibi

\title{
Cloud-Computing Based Early Warning System For Cardiac Emergencies
}

\begin{abstract}
Cardiac emergencies have the critical role in the fatal cases in our country and all over the world. Efficient and on time emergency aid is very important for cardiac emergencies. Heart diseases and emergency cases must be noticed as soon as possible and efforts must be taken quickly. Patients should be taken to the nearest health center. In this study, a new information system which includes relations of patients, doctors and health care centers is developed for remote monitoring of patient's health status. When emergency cases occur, this system automatically informs related individuals and places. To analyze cardiac patient's health states some devices such ECG, Pulse Monitor and Blood Pressure Monitor are used. We developed and used Pulse Monitor device. We also used cloud computing to gather and analyze patient's state records in the flexible, scalable and performance way. Cloud computing is very advantageous to manage and centralize all important patient data. That centralized patient data can be easily and securely used in all platform such as mobile phones, web sites. Cloud application continuously analyze patient data and gives feedback to the doctor's monitor in the emergency cases.
\end{abstract}

Keywords: heart diseases, pulse monitor, cloud computing, mobil service 


\section{Giriş}

Bilişim teknolojilerinin kapasite ve işlemci yeteneklerinin yanında boyutlarında olan olağanüstü gelişmeler ve mekandan bağımsız kullanım imkanı ile uzaktan sağlık hizmetlerinde son yıllarda yapılan çalı̧̧malarda büyük bir artış gözlenmektedir. $\mathrm{Bu}$ konudaki çalışmaları Sørensen ve arkadaşları (Sørensen,2012) 12 derivasyonlu EKG için kullanılabilecek bir platform tanıtmışlardır. Gül F.T. ve arkadaşları ( Gül 2012) ise uzaktan hasta takip için IoT cihazlarında olası kablosuz iletişim teknolojilerinin karşılaştırılmasını vermişlerdir. Kardioloji alanındaki genel çalı̧̧malar Maillard ve arkadaşları (Maillard, 2014) tarafindan ayrıntılı incelenirken , Fransa da kullanım örneklerini Maillard ve arkadaşları (Maillard , 2014) ayrıntılı olarak vermişlerdir. Photoplethysmography(PPG) deriye yakın bölgelerde kan damarlarındaki kan hacim değişikliğini ölçmede kullanılan bir tekniktir. Iş̧ı kaynağının gönderdiği ışığın deri altı dokulardan yansitılan kırmızıdan yakın-infrared bölgeye radyasyon yayılımlarını ölçen photo dedektörler temelinde çalışmaktadır (Mannheimer,2007). Deri altına gönderilen ışı̆̆ın genliğinin değişimi kan hacmindeki farklılıklardan, kan damarlarının yönelimleri ve kalınlıkları ile ilgilidir. PPG sinyalinde temel olarak AC ve DC olmak üzere iki sinyal bulunmaktadır (Mannheimer,2007). AC kısmı foton dedektörü tarafından algılanan kısımdır ve kan hacmindeki değişiklikleri yansıtan asıl sinyaldir. DC kısım ise dokulardan ve kanın standart hacminden kaynaklanan sinyaldir ve gerçek sinyalin analiz edilmesini engellemektedir. DC sinyalini gürültü olarak da tarif edebiliriz. Gürültünün ortadan kaldırılmasından sonra sinyal işlenebilir.

PPG sinyallerini kullanan çeşitli çalışmalar mevcuttur. (Ambekar,2015) ve (Prathyusha ve ark., 2012) bu sinyaller ile solunumu analizi yapmıştır. (Sarkar ve ark., 2012) de sinyaller ile kalp atım hızını belirlemiş̧tir. 


\section{Materyal ve Metot}

$\mathrm{Bu}$ çalışma veri kaynağı parmak ucundaki damarlardaki kırmızı kan hücre miktarıdır. Çalışma kapsamında Şekil 2.1' de şeması verilen elektrik devresi ile nabız değerleri elde edilmektedir. Genelde PPG tekniği, parmak ucu kullanılarak gerçekleştirildiğinden oluşturulan sistemde tasarım ve hassasiyet bakımından en uygun sensör TCRT1000 olarak görülmektedir.

TCRT1000 sensorü Vishay firmasının ürettiği ve içerisinde kızılötesi emiter ve fototransistör bulunduran bir yansıtıcı sensördür. $4 \mathrm{~mm}$ uzaklık hassasiyetine sahip olmakla birlikte emiterkollektör arası 32V'a kadar gerilime karşı dayanıklıdır ve kollektör akımı olarak da maksimum 50mA akım alınabilmektedir. Ayrıca dış ortamdaki 1şıktan minimum oranda etkilenmesi için gün 1şığı filtrelemesine sahiptir. Kızılötesi emiter tarafından yayılan 1şığın karşısındaki cisimden yansımasıyla dedektör diye tabir edilen fototransistörü iletime geçirmesi prensibiyle çalışmaktadır.

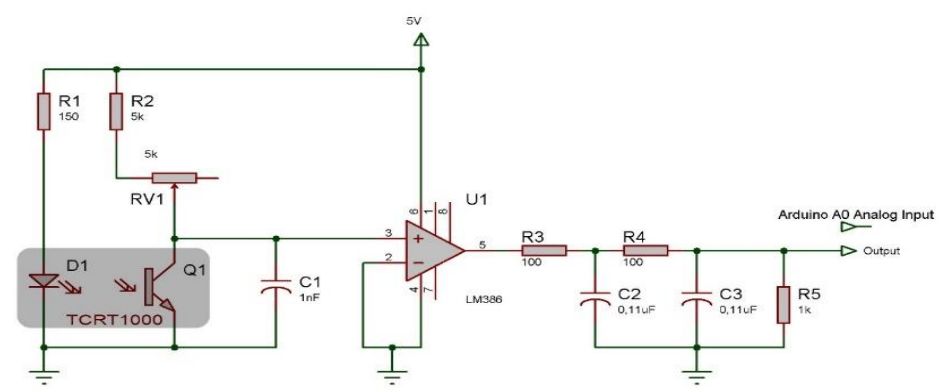

Şekil 2.1. Nabız devresi

Şekil 2.1'de PPG sinyallerini elde etmeyi sağlayan nabız devre şeması görülmektedir. TCRT1000 kullanılarak elde edilen PPG sinyali alçak ve yüksek geçiren filtrelerden geçirilerek istenmeyen $\mathrm{AC}$ ve DC bileşenlerden ayıklanma işlemleri yapıllmış ve mümkün olduğunca az gürültüye sahip sinyaller Arduino’ya iletilmektedir. 


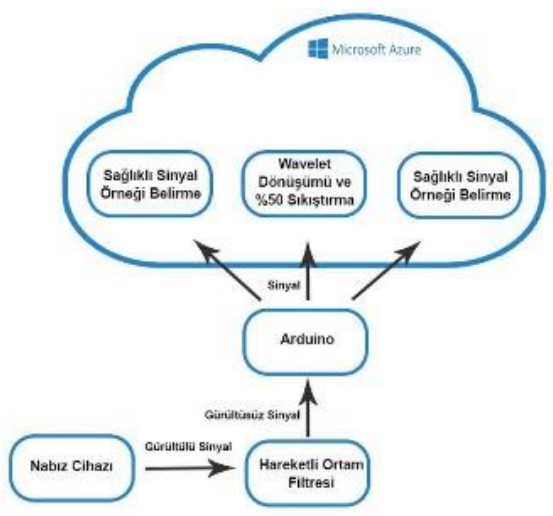

Şekil 2.2. Sinyal iletim grafiği

\subsection{Sinyalin Arduino'ya İletilmesi}

Arduino, mikrodenetleyici programlamayı kolay hale getirmek üzere çeşitli bileşenlerden oluşturulmuş bir platformdur. Üzerinde ATMEL firması tarafından geliştirilen Atmega328 mikrodenetleyicisi bulunmaktadır. Arduino üzerindeki programı yürüten asıl mikrodenetleyici budur. Program belleği 32KB olup, veri belleği ise $2 \mathrm{~KB}$ 'dır. Kart üzerinde bulunan diğer entegre olan Atmega16u2 ise USB bağlantısı için kullanılmaktadır. Ayrıca 14 adet dijital giriş-çıkış pini, 6 adet de analog giriş-çıkış pini bulunmaktadir.

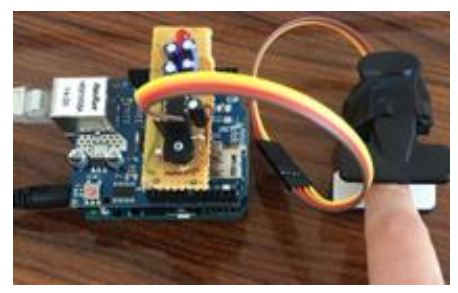

Şekil 2.1.1. Nabız değerinin ölçülmesi

Arduino üzerinde koşan yazılımda her 10ms'de bir analog A0 pininden nabız devresinde elde edilen sinyal değerinin alınması 
sağlanmıştır. Bu pinden okunan değer Arduino'nun kendi iç yapısındaki map işlemi sayesinde 0-1023 arasında alınabilmektedir. Alınan bu değerler diş çevrenin etkisiyle gürültülü olabileceğinden öncelikle bir filtre fonksiyonundan geçmektedir. Eski haline göre daha temiz olan sinyalde tepe noktaları (peak) tespit edilip bu tepe noktaları sayılarına göre dakikadaki nabız sayısı belirlenmektedir.

\subsection{Nabız Değerlerinin Bulut Ortamına Aktarılması}

Hasta kayıtlarının takibi için uc birimler mobil bilişim yani akıllı telefonlar ile, merkezde ise bulut bilişim ile oluşturulmuştur. Bulut bilişim son zamanlarda kullanımı oldukça yaygınlaşmış, pratik uygulamalarda çok büyük avantajları vardır. Sanallaştırma şu an ulaştığı noktada bulut bilişimin temel taşlarından biri niteliğindedir.( Oya, 2011) Bulut bilişim sistemlerinin geliştirilmesinde sanallaştırma teknolojilerinin ne düzeyde kullanılacağı uygulama sahasına (sağlık, eğitim, sigorta, otomotiv v.s.) göre değişmektedir. Normalde bir bilgisayar tabanlı otomasyon sisteminin donanım, yazılım, insan ve süreç gibi bileşenleri bulunmaktadır. $\mathrm{Bu}$ bileșenler donanım bilgisayar sisteminde somut hesaplama yeteneği olan cihazı ve onun yan ekipmanlarını referans eder. Bu sistemlerin satın alınması kiralanması ayrı ayrı süreçler olup her biri ayrıntılı planlama ve bakım-işletme maliyetleri gerektirir. Kullandığımız otomasyon sistemi ile arada sistem yazılımları; işletim sistemleri sürücü yazılımları destek yazılımları ve çeşitli yüksek seviye frameworkler (JVM, .NET v.s.) vardır. Bunun üzerinde bizim otomasyon yazılımı çalışır. Otomasyon yazılımı iç-içe şöyle bir hiyerarşik yapı oluşur. 


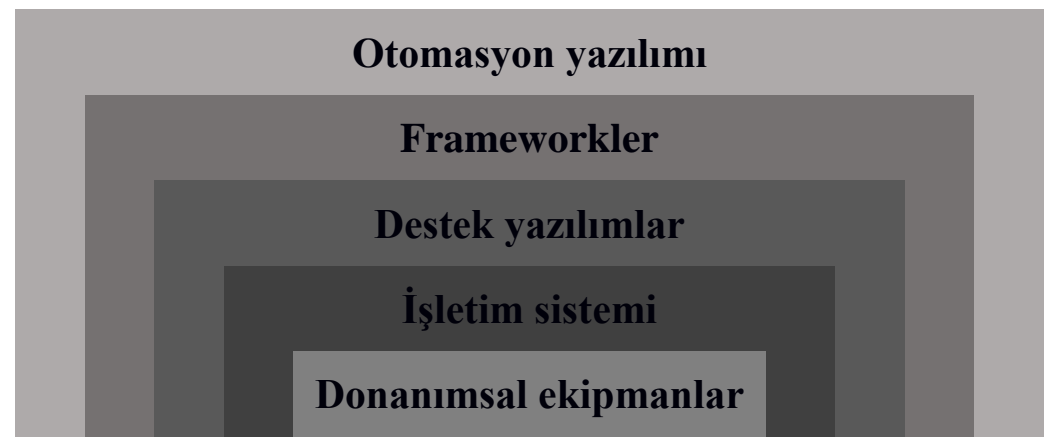

$\mathrm{Bu}$ hiyerarşik yapıdaki her bir katmanın çalışabilmesi kendisinden beklenilenleri yapması için bir alt katman tam çalışır durumda olmalıdır. Dolayısıyla bilgi işlem ekibi bütün bu katmanlardan sorumludur; planlamasını, analizi işletmesini, test ve bakımını yapmak zorundadır. Sistem yükü üzerinden oluşabilecek anlık değişiklikleri iş yükünün artması azalması gibi durumlarda güncelleme yapılması zorunludur. Aksi halde iş yükü artar önlem alınmazsa sistem yetersiz kalır, performans düşüklüğü olur, tersi durumda gereksiz maliyetler ortaya çıkar. Ülkemizdeki ÖSYM sınav dönemi başvuru ve sonuç öğrenme işlemleri, bankalardaki ayın veya yılın belirli günlerinde artan azalan işlem hacmi buna çok iyi örneklerdir. Talebe göre donanım ve yazılım gereksinimleri güncellenmelidir. Bulut bilişim teknolojisi tam bu noktada sistemin soyut bir yapıymış gibi çalışmasını sağlar. Bulut bilişim teknolojisinde işletme açısından bir yük olan işler ve sorumluluklar (sistem odaları, jenaratörler, UPS cihazları, iklimlendirme, güvenlik v.s.) servis sağlayıcı hizmeti sağlayan firmaya ait olmaktadır. Servis sağlayıcı, servisi planlayıp kurar ve tüketiciye ulaştırır. Sunduğu servisler temel olarak, altyapı (IaaS), platform (PaaS), yazılım (SaaS) servisleridir. ( Hakan,2012)

1. IaaS- ( Infrastructure as a Service ) Donanımın Servis edilmesi; uzaktan erişime açılmış, konfigürasyon ayarlaması işlemci, bellek, veri yolu kapasitesi gibi parametreleri çok hızlı değişebilen çok yetenekli bilgisayarın donanımında sanallaştırma yaparak ortak kullanım sağlanır. Avantajları arasında hız kazancı 
maliyet düşüklüğü ve esneklik söylenebilecek, tüm donanım kaynağın özellikle verinin karşı tarafta tutulması düşüncesi güvenlik konusunda kaygı ve tedbirleri beraberinde getirir.

2. PaaS- ( Platform as a Service ) Platformun Servis Edilmesi; Bir alt katman olan hardware ve işletim sistemi ile ilgilenmeyip bunların bütün bakım ve işletimini soyutlayarak platformun kullanımıdır. İşe odaklanma gibi çok büyük avantajları vardır.

3. SaaS- ( Software as a Service) Yazılımın Servis Edilmesi; günlük hayatımızda artık girmiş oldukça yaygın bir kullanımı vardır, artık yazılımlar uzaktaki bir sistemde yüklü bir istemci yazılımı ile hizmetçi makine üzerindeki yazlımlar kullanılabilmektedir.

Elde edilen nabız değerlerinin bulut ortamına aktarılması işlemi Microsoft Azure'un Mobil Services özelliği kullanılarak gerçekleştirilmektedir. Devrede oluşan voltaj farkı değeri Ardiuno IoT cihazı ile işlenmekte ve önişleme, gürültü temizleme ve periyodun bulunması sağlanmaktadır. Verinin bulut ortamında işlenmesi ve periyodun bulunmasında smooth ve wavelet sinyal işleme algoritmaları kullanılmaktadır. Mobil servisi kullanılarak elde edilen veriler http protokolu destekli restful API ile istemci sistemlere sunulmaktadır. Son y1llardaki artan internet ve istemci/sunucu heterojen sistemlerin yaygın kullanımı ile rest api servisleri büyük bir önem kazanmıştır. İngilizce REpresentational

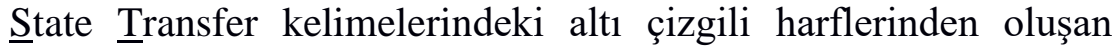
REST kisaca API ( application program interface ) için bir mimari yalaşım modelidir. Daha yaygın kullanılmakta olan RESTful ise bu hizmeti sağlayan sisteme verilen bir addır. Mimari modeller daha ziyade üst seviye veri modelleme ve hizmet tanımlamada kullanılır. Veri aktarımını için GET, SET, PUT, DELETE işlemlerini desteklenmektedir. Veri formatı olarak XML, JSON, TXT, HTML gibi istenen veri türünde değerler döndürebilir. Özellikle XML ve JSON veri formatı web uygulamalarında yaygın olarak 
kullanılmaktadır. Veri kaynakları URI standardında olduğu gibi isimlendirilmektedir.

Örneğin geliştirilen sistemdeki REST API'nin kullanımında "ecardio.azurewebsites.net/api/doctor/kadir" doktor kadir hakkındaki bilgileri, .../api/ambulance/Yildirim" ise Yildirim isimli vatandaşımıza en yakın 5 ambulansın konum bilgilerini getirmektedir.

\subsection{Hareketli Ortalama Filtresi (Moving Average Filter)}

Hareketli Ortalama Filtresi basit olmakla beraber, beyaz gürültü basit gürültüleri sinyalden temizleyerek sinyali işlem yapılabilir bir hale getirmektedir. Hareketli ortalama filtresi aşağıdaki denklem ile ifade edilebilir (Smith, 1999):

$$
y[i]=\frac{1}{M} \sum_{j=0}^{M-1} x[i+j]
$$

Burada kullanılan Msayısı, hareketli ortalaması alınacak olan örnek sayısını göstermektedir. Kullanılan $M$ sayısının seçimi oldukça önemlidir. . Çalışmamızda hareketli ortalama filtre sinyaldeki beyaz gürülttüyü ortadan kaldırmak ve sinyali düzleştirmede kullanılmıştır. Bu filtreden önceki ve sonraki sinyal aşağıdaki Şekil 2.3.1'den görülebilir. 

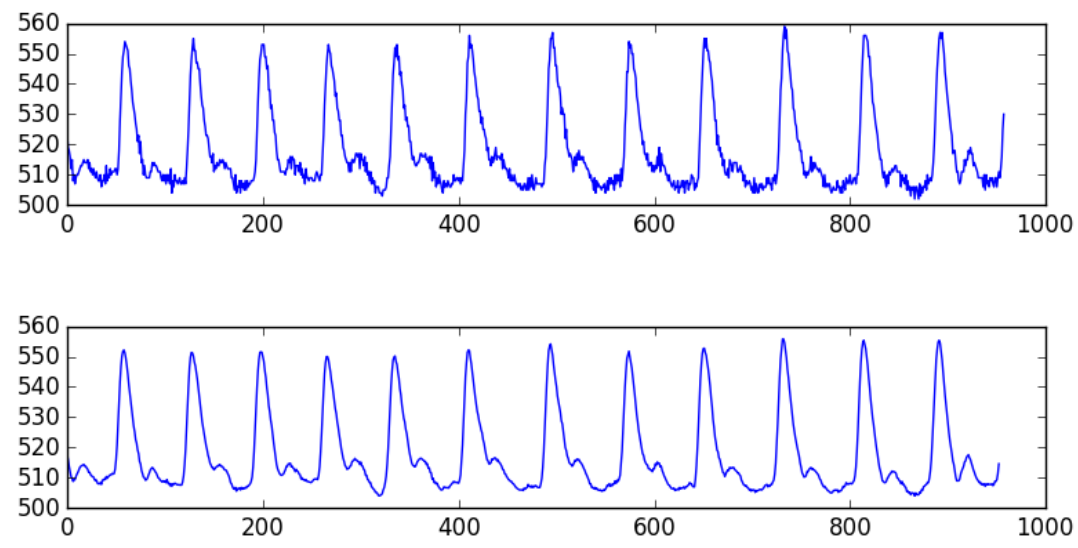

Şekil 2.3.1. Gürültülü ve Gürültüsüz sinyal

\subsection{Tepe Noktası Belirleme}

Sinyal, gürültüden arındırıldıktan sonra çalışma zamanında istatistik uygulanmış ve tepe noktaları bulunmuştur. Sinyal deki tepe noktasının sinyal verilerinin ortalama değerinden büyük olması ve o noktada sinyal verisinin eğim değiştirmesi bu amaçla kullanılmıştır. Sinyal verisi dedektörden sürekli olarak okunduğu için çalışma zamanında sinyal verilerinin ortalaması ve standart sapması için aşağıdaki formüller kullanılmıştır (Smith, 1999).

$$
\begin{gathered}
\mu=\frac{1}{N} \sum_{i=0}^{N-1} x_{i} \\
\sigma^{2}=\frac{1}{N-1}\left[\sum_{i=0}^{N-1} x_{i}^{2}-\frac{1}{N}\left(\sum_{i=0}^{N-1} x_{i}\right)\right]
\end{gathered}
$$

$\mathrm{Bu}$ yöntem ile tespit edilen tepe noktaları Şekil 2.4.1.'de görülmektedir. 


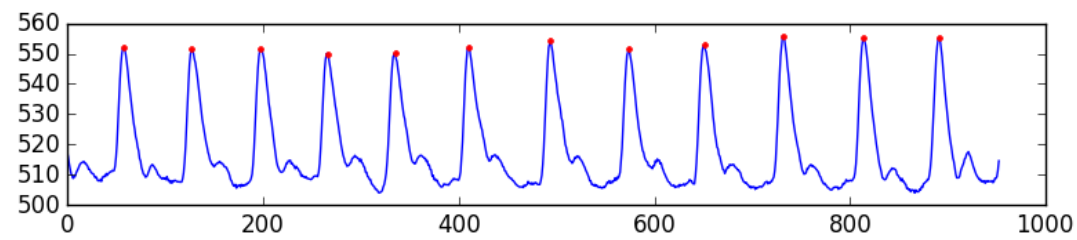

Şekil 2.4.1. Tepe noktası belirlenen sinyal

Herhangi bir anomalisi olmayan sinyalde tepe noktaları arasındaki mesafe kalp atımı ile orantılı olarak birbirlerine yakındır. İki tepe noktası arasındaki mesafe ve eğim anomali tespitinde kullanılmıştır.

$$
\begin{gathered}
l_{i}=\left|t\left[p_{i+1}\right]-t\left[p_{i}\right]\right| \\
\alpha_{i}=\frac{y\left[p_{i+1}\right]-y\left[p_{i}\right]}{t\left[p_{i+1}\right]-t\left[p_{i}\right]}
\end{gathered}
$$

Burada $\boldsymbol{y}[\boldsymbol{i}]$ sinyal, $\boldsymbol{t}[\boldsymbol{i}]$ zaman olmak üzere, tepe noktaları arasındaki mesafe $\boldsymbol{l}_{\boldsymbol{i}}$, tepe noktaları arasındaki eğim de $\boldsymbol{\alpha}_{\boldsymbol{i}}$ ile gösterilmektedir.

\subsection{Dalgacık (Wavelet) Dönüşümü}

Dalgacık dönüşümü veri sıkıştırma(Bruylants,2015), nesne tan1ma(Zhang,2004), sayısal analiz(Li,2014) vb. gibi birçok sinyal işleme çalışmalarında kullanılmaktadır. (Mallat, 1989) da dalgac1k dönüşümünün çoklu-çözünürlük uygulamalarını açıklamıştır. Dalgacık dönüşümü sinyali yaklaşık sinyal ve detay sinyal şeklinde iki parçaya ayırır. Yaklaşık kısımlara tekrar tekrar dalgacık dönüşümü uygulanarak çok-seviyeli dalgacık dönüşümü meydana getirilebilir (Akansu et al.,2010). 
Temel olarak dalgacık dönüşümü $\boldsymbol{L}^{\mathbf{2}}(\mathbb{R})$ deki bir $\boldsymbol{f}(\boldsymbol{t})$ fonksiyonunu $\boldsymbol{L}^{2}\left(\mathbb{R}^{2}\right)$ deki $\boldsymbol{W}_{\boldsymbol{f}}(\boldsymbol{a}, \boldsymbol{b})$ sinyaline dönüştürür. Buradaki $(\boldsymbol{a}, \boldsymbol{b})$ sürekli değerlerdir ve ölçekleme ile kaydırma parametresi adlanır(Akansu et.al,2010). Sürekli-dalgacık dönüşümü aşağıdaki gibi tanımlanabilir(Daubechies,1988).

$$
\begin{gathered}
W_{f}(a, b)=\left\langle f(t), \psi_{a b}(t)\right\rangle=\int_{-\infty}^{\infty} f(t) \psi_{a b}(t) \\
f(t)=\frac{1}{c_{\psi}} \int_{-\infty}^{\infty} \int_{0}^{\infty} \frac{d a d b}{a^{2}} W_{f}(a, b) \psi_{a b}(t)
\end{gathered}
$$

Burada $\boldsymbol{C}_{\boldsymbol{\psi}}$ normalleştirme parametresidir ve aşağıdaki gibi tanımlanmaktadır.

$$
C_{\psi}=\int_{0}^{+\infty} \frac{|\psi(\Omega)|^{2}}{\Omega} d \Omega<+\infty
$$

Bunun a ve b parametreleri ayrık hale getirilerek dalgacık dönüşümünün ayrık hali aşağıdaki gibi tanımlanabilir.

$$
\begin{gathered}
a=\boldsymbol{a}_{0}^{m}, b=n b_{0} a_{0}^{m} \\
\left\{\psi_{m n}(t)\right\}=\boldsymbol{a}_{0}^{\frac{-m}{2}} \psi\left(\boldsymbol{a}_{0}^{-m} t-n b_{0}\right) m, n \in Z
\end{gathered}
$$

Buradaki $\left\{\boldsymbol{\psi}_{m \boldsymbol{n}}(\boldsymbol{t})\right\}$ kümesi tam olduğunda herhangi bir $\left\{\boldsymbol{\psi}_{m n}(\boldsymbol{t})\right\}$ fonksiyonunu bu kümenin elemanları ile aşağıdaki gibi ifade edebiliriz.

$$
f(t)=\sum_{m} \sum_{n} d_{m, n} \psi_{m n}(t)
$$

Burada $\boldsymbol{d}_{\boldsymbol{m}, \boldsymbol{n}}$ dalgacık dönüşümü katsayılarıdır ve aşağıdaki gibi ifade olunurlar.

$$
d_{m, n}=\left\langle f(t) \psi_{m n}(t)\right\rangle=\frac{1}{a_{0}^{m / 2}} \int f(t) \psi\left(a_{0}^{-m} t-n b_{0}\right) d t
$$

$\boldsymbol{\psi}_{m n}(\boldsymbol{t})$ ler tam olsalar da baz değillerdir bu nedenle ölçekleme fonksiyonları $a_{0}=2, b_{0}=1$ için aşağıdaki gibi tanımlanır. 


$$
\begin{gathered}
\left\{\phi_{m n}(t)\right\}=2^{-m / 2} \phi\left(2^{-m} t-n\right) \\
\int \phi_{m n}(t) \phi_{m s}(t)=\delta_{n-s}
\end{gathered}
$$

$\boldsymbol{f}(\boldsymbol{t})$ nin ölçekleme parametreleri aşağıdaki gibi bulunabilir.

$$
c_{m, n}=\left\langle f(t) \phi_{m n}(t)\right\rangle=\frac{1}{2^{m / 2}} \int f(t) \phi\left(2^{-m} t-n\right) d t
$$

$\mathrm{Bu}$ iki fonksiyon kümesi kullanılarak $\boldsymbol{f}(\boldsymbol{t})$ aşağıdaki gibi ifade edilebilir.

$$
\begin{aligned}
& f(t)= \\
& \begin{array}{l}
\sum_{n=\infty}^{+\infty} c_{L, n} 2^{-L / 2} \phi\left(\frac{t}{2^{L}}-n\right)+ \\
\quad \sum_{m=1}^{L} \sum_{n=-\infty}^{+\infty} d_{m, n} 2^{-m / 2} \psi\left(\frac{t}{2^{m}}-n\right)
\end{array}
\end{aligned}
$$

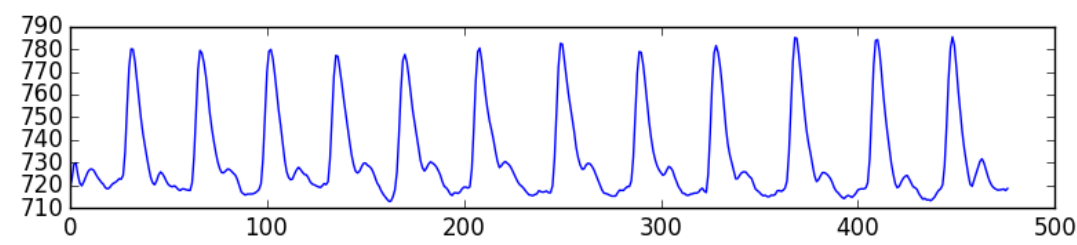

Şekil 2.5.1. Dalgacık dönüşümünden sonra elde edilen sinyal

Çalışmamızda Daubechies dalgacık dönüşümü ve ters dönüşümü kullanıldı. Bu sayede girdi sinyalinin \%50 oranında sıkıştırılması sağlanmıştır. Sağlık sensörlerinden gelen verinin sürekli olduğunu düşündüğümüzde bu verilerin tamamının veri tabanında saklanması fazla yere ihtiyaç duyacağından bu yöntem tercih edilmiştir. Dalgacık dönüşümü için PyWavelet paketi kullanılmıştır(Wasilewski,2006). Dalgacık dönüşümünden sonraki sinyalin yaklaşık kısmı aşağıdaki şekil 2.5.1 de görülebilir. 


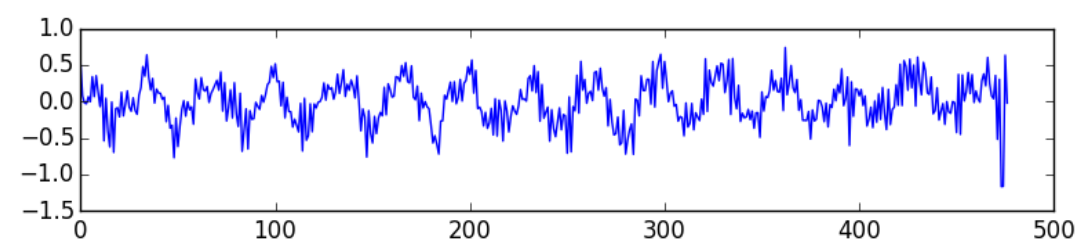

Şekil 2.5.2. Sinyalin detay değerleri

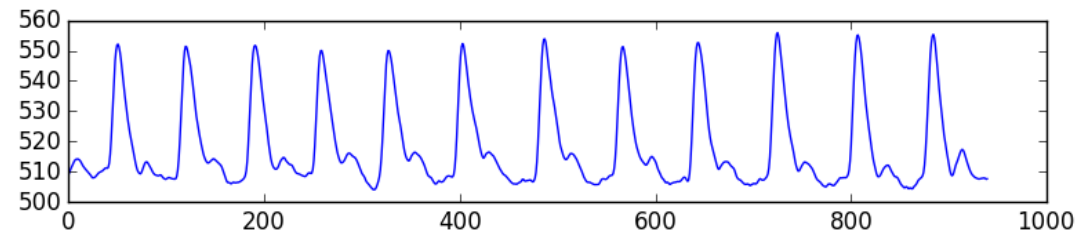

Şekil 2.5.3. Sinyalin orijinal hali

Detay sinyalinin tamamını veri tabanında saklamadan sadece aritmetik ortalamasını saklayarak orijinal sinyali oluşturabiliyoruz. Bu şekil 2.5.3 de görülebilir.

Ayrıca anomali tespitinde sadece yaklaşık sinyal kullanımı ile aynı bilgiler elde edilebiliyor. Bu bağlamda yaklaşık sinyalde hareketli filtre ve tepe noktası bulma algoritmaları uygulandığında şekil 2.5.4 deki bilgiler elde edilmektedir.

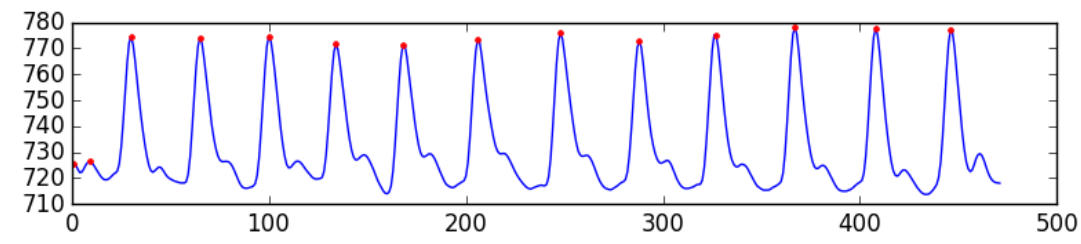

Şekil 2.5.4. Yaklaşık sinyalde anomali tespiti 


\subsection{Anomali Tespiti}

Anomali olan bir sinyal Şekil 2.6.1.'de gösterilmektedir.

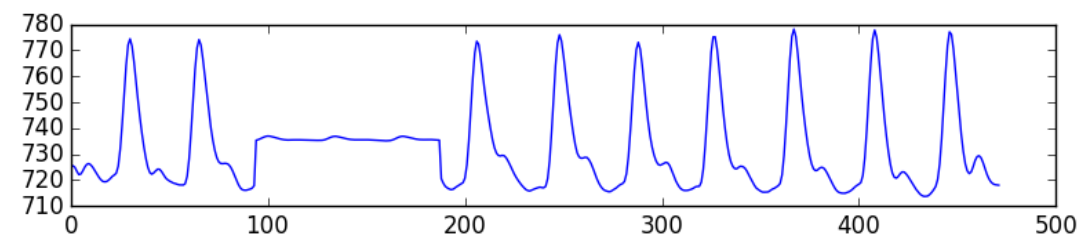

Şekil 2.6.1. Anomali olan sinyal

$\mathrm{Bu}$ sinyalin tepe noktalarının ve anomali kısmının belirgin olması için Grover arama algoritmasının genlik yükseltme yöntemi kullanılmıştır(Grover,1996). Bu yöntem ve tepe noktası belirleme işleminden sonra sinyal Şekil 2.6.2.'deki gibi olur.

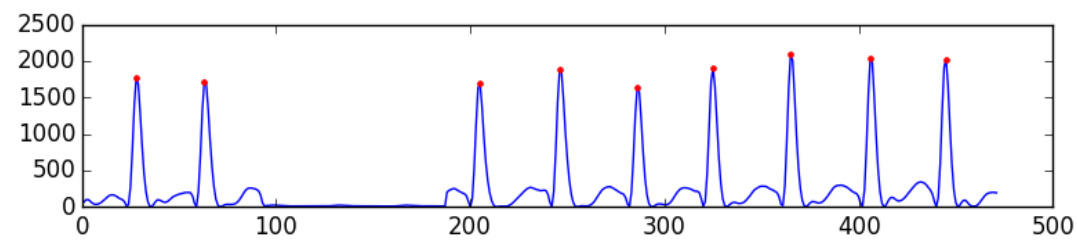

Şekil 2.6.2. Grover ile anomali tespiti

$\mathrm{Bu}$ sinyaldeki tepe noktaları arasındaki mesafelerin farkları, eğim farklılıkları ve kalp atım hızındaki farklılık noktaları birlikte kullanılarak anomali durumu tespit edilmekte ve buluttaki alarm durumu tetiklenmektedir. Bu tetiklenme sonucunda ilgili(doktor, yakın, sağlık kuruluşu vb) kişinin sisteminde farklı durumun sinyali görüntülenmektedir. Anomali durumu tespit edilmiş olur. 


\section{Sonuç}

Geliştirilen sistem kalp rahatsızlığı olan kişilerin nabız verisinin ölçülmesi ve mesafe engeli olmaksızın bu verinin merkezi bulut sistemi üzerinden doktor ve hastane ile paylaşım imkanı sağlanmıştır. Hastaların uzaktan takip ve kontrolü her iki tarafa da büyük kolaylıklar getirmekte, hastanelerde oluşacak iş yükünü azaltma konusunda iyileştirici rol oynama potansiyelini ortaya koymaktadır. Erken teşhisin çok daha önceden devreye girmesiyle oluşabilecek olan riskli durumları önlemek gibi avantajları da mevcuttur. Kalp rahatsızlı̆̆ı olan kişilerin hastane ziyaretleri azalmakta, doktoru ile teması sürekli hale gelmekte ve yaşam kalitesi yükseltilmesinin yanı sıra olası yaşam riskleri en az seviyede tutulmaktadır. Hastanın ölçüm işlemi ve verinin merkezi sisteme iletilmesinden sonra sonuçlar üzerinde yapılan bir inceleme ile normal sınırlar dışında kalan veriler tespit edilerek, hastanın sistemde kayıtlı olan yakınlarına, doktoruna otomatik olarak bilgilendirme yapılmaktadır. Doktorun önerileri ile tedavi süreci belirlenir veya gerekiyorsa acil müdahale edilerek hayati riskler en az indirgenebilir. Bu noktada uzaktan takip için bulut bilişim ve mobil servislerin kullanımı gelecekte daha artacak sağlık alanında günlük hayatımızın bir parçası olacaktır. 


\section{Kaynakça}

Akansu A.N., Serdjin W.A., and Selesnick, (2010). Wavelet Transforms in Signal Processing: A Review of Emerging Applications, Physical Communication, Elsevier, vol:3, issue 1, pp. 1-18. (Ulusal - Uluslararası Makale)

Ambekar M.R., Prabhu S., (2015). A Novel Algorithm to Obtain Respiratory Rate from the PPG Signal. International Journal of Computer Applications. Vol: 126.

Bruylants T., Munteanu A, Schelkens P.,(2015). Wavelet based volumetric medical image compression, Signal Processing: Image Communication, Vol. 31, pp. 112-133.

Çetinkaya A., (2014). http://www.minepla.net/2014/08/wcf-ileasp-net-web-api-nedir (Web Adresleri)

Gavrylyuk K., (2016). https://azure.microsoft.com/enus/documentation/articles/ app-service-mobile-value-prop (Web Adresleri)

Grover L, (1996). A Fast Quantum Mechanical Algorithm for Database Search. Proceedings of the 28th Annual ACM Symposium on the Theory of Computing, pp.212-219.

Gül F.T., Akif K.(2012) Giyilebilir EKG Uygulaması ve Kullanılabilir Kablosuz İletişim Teknolojilerinin Karşılaştırılması, Akademik Bilişim 2012

I. Daubechies, (1988). Orthonormal bases of compactly supported wavelets, Comm. Pure Appl. Math. 909996.

Jui-chien Hsieh, Meng-Wei Hsu (2012) A cloud computing 
based 12-lead ECG telemedicine service. BMC Medical Informatics and Decision Making

Kurtz J.,Wortman B., 2014. ASP.NET Web API 2: Building a REST Service from Start to Finish

Li B., Chen X.,(2014). Wavelet-based numerical analysis:

A review and classification, Finite Elements in Analysis and Design, Vol. 81, pp. 14-31.

Mallat S., (1989). A Theory for Multiresolution Signal Decomposition: The Wavelet Representation., IEEE Pattern Analysis and Machine Intelligence, vol. 11, no:7, pp. 674-693. (Ulusal - Uluslararası Makale).

Mannheimer Paul D., (2007). The Light-Tissue Interaction of Pulse Oximetry. Anesthesia \& Analgesia Vol. 105, No. 6, (Ulusal - Uluslararası Makale).

Maillard N, Perrotton F, Delage E, Gourraud JB, Lande

G, Solnon A, Probst V, Grimandi G, Clouet J. (2014).

Cardiac remote monitoring in France. Archives of

Cardiovascular Diseases 2014 Apr;107(4):253-60

Oya Ş. (2011), Bulut Bilişim, Akademik Bilişim 2011

Hakan Y.(2012), Bulut Bilişim El Kitabı

Prathyusha B. Rao T. S., Asha D., (2012). Extraction of Res piratory Rate from PPG Signals Using PCA and EMD, International Journal of Research in Engineering and Technology. 
Sarkar S., Bhoi A. K., ve Savita G. ,(2012). Fingertip Pulse Wave Analysis and Heart Rate Detection. International Journal of Emerging Technology and Advanced Engineering. Vol:2.

Smith Steven W., (1999). The Scientist and Engineer's Guide to Digital Signal Processing. Second Edition (Kitap İçinde Bölüm).

Sørensen J.T., Clemmensen P., Sejersten M. (2012)

Telecardiology: past, present and future. Revista Esponela de Cardiologia

Taşdemir C., (2014). Arduino Uygulamaları Kitabı. (Kitap İçinde Bölüm)

Vishay, (2012). http://www.vishay.com/docs/83752/tcrt1000.pdf, (Datasheet).

Wasilewski F. (2006). PyWavelet, Analysis and Classification of Medical Signals using Wavelet Transforms. http://www.pybytes.com/pywavelets/.

Weeks M., (2007). Digital Signal Processing Using Matlab and Wavelets.(Kitap İçinde Bölüm).

Zhang X., Younan N.H., (2004). A Wavelet-Based Automated Object Recognition System for Remotely Sensed Images, Proceedings of the International Conference on Imaging Science, Systems and Technology ,pp. 391-398. 